\title{
How Much Capital Does a Reinsurance Need?
}

\author{
Jean-Luc Besson, Michel M. Dacorogna, Paolo de Martin, \\ Michael Kastenholz and Michael Moller \\ SCOR, General Guisan, Quai26, Zurich 8022, Switzerland.
}

A modern reinsurance company needs to manage its capital efficiently. The problem is that there are many views on capital, depending on the various positions of the stakeholders of the company involved. In this paper, we present a consistent way of defining capital and of managing it, taking into account the view of all stakeholders. We answer the question of how much capital is required by the business, and introduce the notion of buffer capital. This is used to reduce the likelihood of the company having to call too often on its shareholders to refurbish its capital. We show how this concept relates to the setting of return on equity objectives for the company. Capital allocation is the driver for measuring the economic performance of a business. The fixing of limits relating to capital consumption is linked to capital allocation because it preserves the diversification of the book. We advocate the use of the internal model to determine all of these parameters, and to set the stage for good enterprise risk management within the company.

The Geneva Papers (2009) 34, 159-174. doi:10.1057/gpp.2009.8

Keywords: risk-based capital; portfolio management; capital allocation

\section{Introduction}

In financial institutions, the primary focus of capital is not mainly to provide finance, but more to absorb the risks undertaken. Capital allocation is thus not ancillary to business processes; it should be at their heart. It is a precondition for the optimisation of shareholder value for financial institutions ranging from banks to insurance and reinsurance companies ${ }^{1}$.

Although such questions have been at the centre of the debate for banking and insurance regulation for many years, ${ }^{2}$ the recent crisis of financial markets, where the capital of some banks was leveraged 40 times, illustrates the importance of determining the adequate level of capital to avoid major dislocation of the markets. Surely, progress still needs to be made to fully capture the risks in models so that realistic amounts of capital are computed and required from management. There are many books that treat the subject of capital management mostly from the point of view of banks ${ }^{3}$ or investments. ${ }^{4}$ However, very few deal with insurance and reinsurance although those two institutions have strong and specific needs for capital

\footnotetext{
${ }^{1}$ Morisano (1998).

2 Basel Committee (1988).

${ }^{3}$ Matten (2000); Crouhy et al. (2001).

${ }^{4}$ Bernstein (2007).
} 
and have also developed sophisticated techniques themselves to look at this problem ${ }^{5}$ that have, until now, served their purpose well.

In this paper, we show how a clear capital management and allocation process can help a reinsurance company to steer its risk portfolio towards profitability. We focus on reinsurance because it is our business, but we believe that with a few adaptations, the principles presented here can also be applied to insurances. In the first section, we present the various views on capital that will determine the choice of capital required to run the business. The available capital is defined in the Section entitled "The available capital from the shareholder's point of view", while the amount of capital required by the business is defined in the Section entitled "How much capital does the business require?" The last part of the paper is dedicated to capital allocation, capital management and limit-setting; then the conclusions are drawn. In the appendices, we formally show the difference between regulators and management approaches to capital (Appendix A), the link between the buffer capital and return on equity (ROE) (Appendix B). The last appendix is a glossary defining and explaining the terminology used in the text (Appendix C).

\section{The different views on capital}

There are many stakeholders in an insurance company. The major ones are the shareholders, the policyholders and their representatives, the regulators, the rating agencies, and the management and employees. For each of them, the capital of the company plays a different role:

- From the point of view of management, capital is the means by which to generate business and profit, and it should be managed in such a way as to satisfy all other stakeholders.

- For policyholders and regulators, capital is the guarantee for liability payments that exceed expectations. It should thus be as large as possible.

- For shareholders, capital is the monetary "value" of a firm for its "owners". It is used to generate future profits, and should stay as small as possible (target capital). The shareholder's concern is that the riskiness of the company's activities is properly compensated for in the form of returns generated on his investment.

- For rating agencies, capital equals the monetary value of a company. The rating agencies use this capital to assess the creditworthiness and potential risk of a company. Rating agencies conduct an assessment of "sufficient" capital levels on the basis of the balance sheet and management meetings.

The shareholder's perspective is arguably the most important, as it drives the optimisation of shareholder returns, which is (or should be) the prime objective of the managers of a publicly traded company. His perspective starts with the share price, which implicitly contains the expectation of future profit. This will of course influence our definition of risk. The risk for the shareholder is that the company will not achieve its expected profit.

\footnotetext{
${ }^{5}$ Shimpi et al. (1999).
} 


\section{The available capital from the shareholder's point of view}

From the investor's point of view, the available capital starts from the amount of equity reported on the balance sheet of a company. ${ }^{6}$ It can then be adjusted to obtain the economic capital:

$$
A C=E Q+H D-G O-D T A+A D J_{L}+A D J_{A}
$$

where $A C$ is the available capital, $E Q$ is the equity reported on the balance sheet, $H D$ is the hybrid debts, $G O$ is the goodwill, $D T A$ is the net deferred tax asset, and $A D J_{L}$ and $A D J_{A}$ the adjustments made for market consistent valuation of the liabilities and the assets, ${ }^{7}$ respectively. Starting from the equity reported on the balance sheet, the investor will look at how much return the company generates on it, and he will judge the profitability of his investment by comparing the profit the company declares with the capital it holds. It is important to understand that the assessment of the available capital and the required capital has to refer to the same period. This means that the available capital at the beginning of the assessment period contains the expected economic profit, or equivalently, is assessed at the end of the period according to Eq. (1).

Bearing this in mind, let us analyse the process that management has to go through in order to define the amount of capital needed as well as the profitability targets. The aim of this paper is to answer the following questions:

- How much capital does the business require (required capital)?

- How does the profitability target in terms of ROE translate to the required profitability of the business?

\section{How much capital does the business require?}

Required or target capital is the monetary value a company needs to have according to the risk assessment of that company by a stakeholder or stakeholder's agent (rating agencies, regulators, investors, management). How much is the investor willing to lose? How well is a policyholder protected? This is basically the risk-based capital $(R B C)$ plus some "buffer capital" on top of it. All of these quantities are computed at $t_{0}$ for the given time horizon, $t_{1}$, generally one year. This $R B C$ must be compared to the available capital. In Figure 1, we illustrate the distinction between the available capital and the $R B C$.

Although this definition seems simple, we should remember that various stakeholders have different views on the $R B C$, depending on their risk tolerance as well as on their depth of knowledge about the risks and their inter-dependencies within a company. To compute its $R B C$, a reinsurance company needs to define a risk measure and a risk tolerance level. We propose using the expected shortfall of the

\footnotetext{
${ }^{6}$ Clearly this is neither the sole source of information nor the sole view of capital for the investors. They can also use the share price to compute the market capitalisation, which includes the expectation of future cash flows for future business.

${ }^{7}$ The adjustments for assets include negative discounting effects on assets like reinsurance assets.
} 


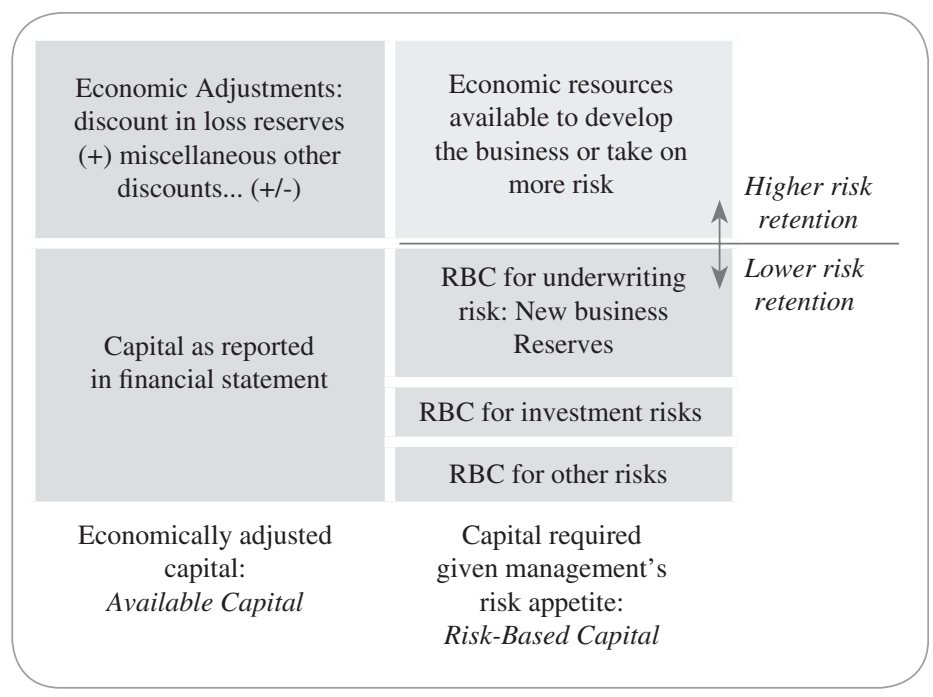

Figure 1. The two dimensions of capital of an insurance company: available vs. required capital.

firm's economic capital at the 99 per cent level. ${ }^{7 b}$ This measure is also used in the Swiss Solvency Test, and has the major advantage ${ }^{8}$ of being mathematically coherent. ${ }^{9}$ This property crucially permits an additive allocation of the capital to individual risks. As a general rule, the company will estimate its $R B C$ from its internal model (a precise definition of $R B C$ is given in Appendix A). The internal model represents the highest level of knowledge concerning the risks involved in the portfolio. However, in order to accommodate the various stakeholders, the required capital for running the business needs to amount to the maximum of the $R B C$ from the internal model, the rating agency's model (at the required rating level, for instance $\mathrm{A}+$ for $\mathrm{S} \& \mathrm{P}$ ), and the solvency capital. Moreover, the management of the company will want to add some buffer capital to this required capital to protect itself from having to go to the market to raise capital too often, and to account for model uncertainty. We have seen during the current financial crisis how wrong certain model assumptions can be in stress situations, particularly those related to dependence between risks. In Figure 2, we illustrate how we come to the various capitals (which are precisely defined in the glossary).

A convenient way of determining this buffer capital is to calculate it using the internal model. From the internal model, we also deduce the probability distribution of shareholder equity after one year. To determine the buffer capital, we add to the required capital the quartile of the distribution, which has a 10 per cent probability of being exhausted. In simple terms, this means that management does not want to go

\footnotetext{
${ }^{7 b}$ In monetary amount, this generally corresponds quite closely to the capital required from a Value-atRisk at a 99.6 per cent level.

${ }^{8}$ The sum of all allocated capital is equal to the RBC for the entire portfolio (Artzner et al., 1999).

9 Artzner et al. (1997).
} 


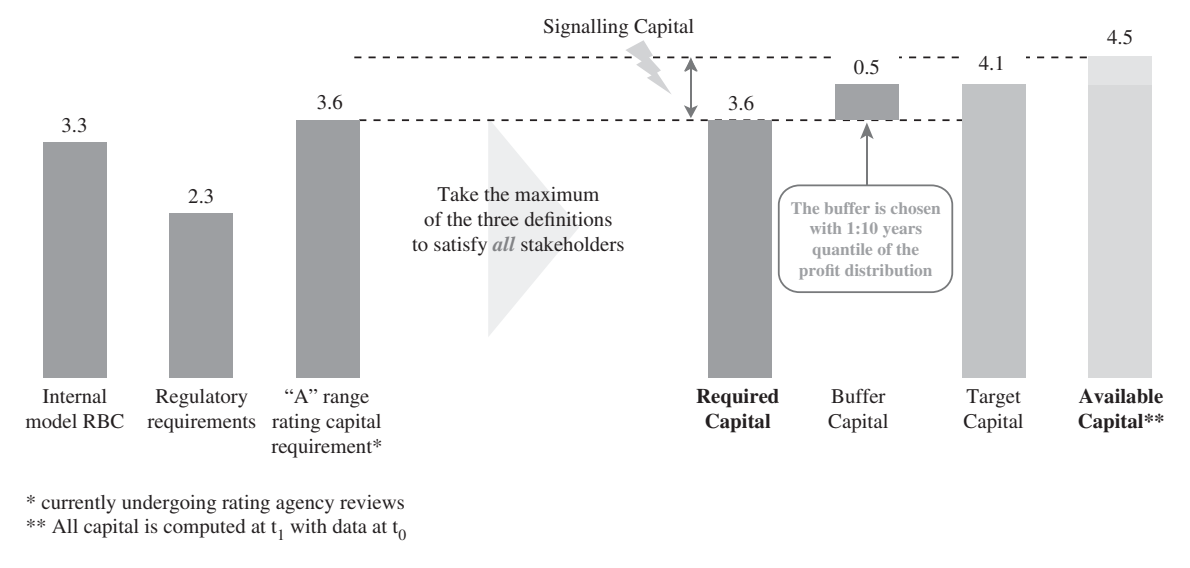

Figure 2. The internal capital requirement satisfies all stakeholders: internal $R B C$, Required Capital, Buffer and Target Capital (in $€$ billons, based on figures for 2008).

back to the capital market to ask for a capital increase after big losses more than once every 10 years. In Figure 3, we illustrate the choice described here.

This threshold depends, of course, on the company's risk appetite and its access to financial markets, as well as on the market expectations regarding company profitability. If management fixes the target ROE, this will automatically set limits on the size of the buffer. An acceptable range should be between 5 and 15 years. Given the company risk/return profile, the 10 per cent value corresponds more or less to the target ROE of 900 bps above the risk-free rate proposed by SCOR management. In other words, proposing a target ROE is directly linked to the quantile of the buffer.

The size of the buffer capital is derived by a risk-return trade-off. The lower the recapitalisation probability, the more buffer capital is required. The higher the target capital (the sum of the required capital and the buffer capital), the smaller the ROE is for a given profit. Such a trade-off can be found on the risk-return curve produced by the model once the target ROE has been determined, as shown in Figure 4. In Appendix B, we compute how the size of the buffer and the target ROE are functionally related.

An alternative way to check the reasonableness of the buffer is to compare its amount to the results of the evaluation of extreme scenarios and see whether the buffer covers a good portion of them, as illustrated in Figure 5.

\section{Capital allocation and performance}

Once we have agreed on how to calculate the target capital and have derived it, there are two questions left: what will we do with possible excess capital, and how will we 


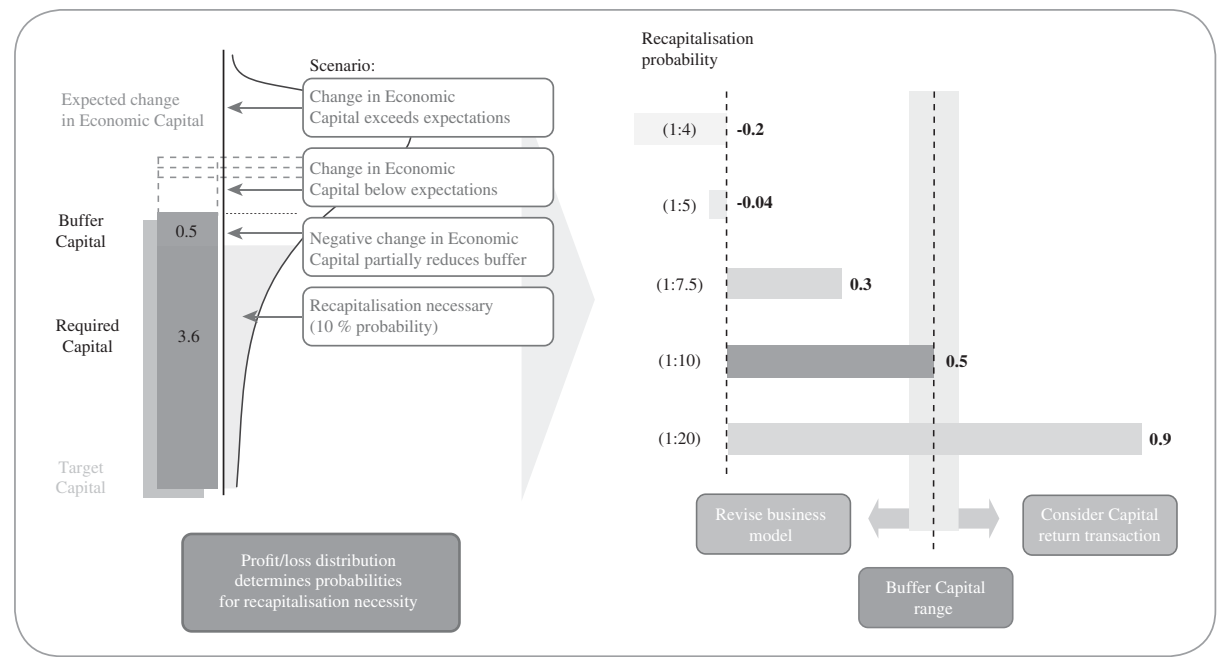

Figure 3. SCOR actively manages its capital to optimise return Buffer Capital limits probability of a capital increase (in $€$ billions).

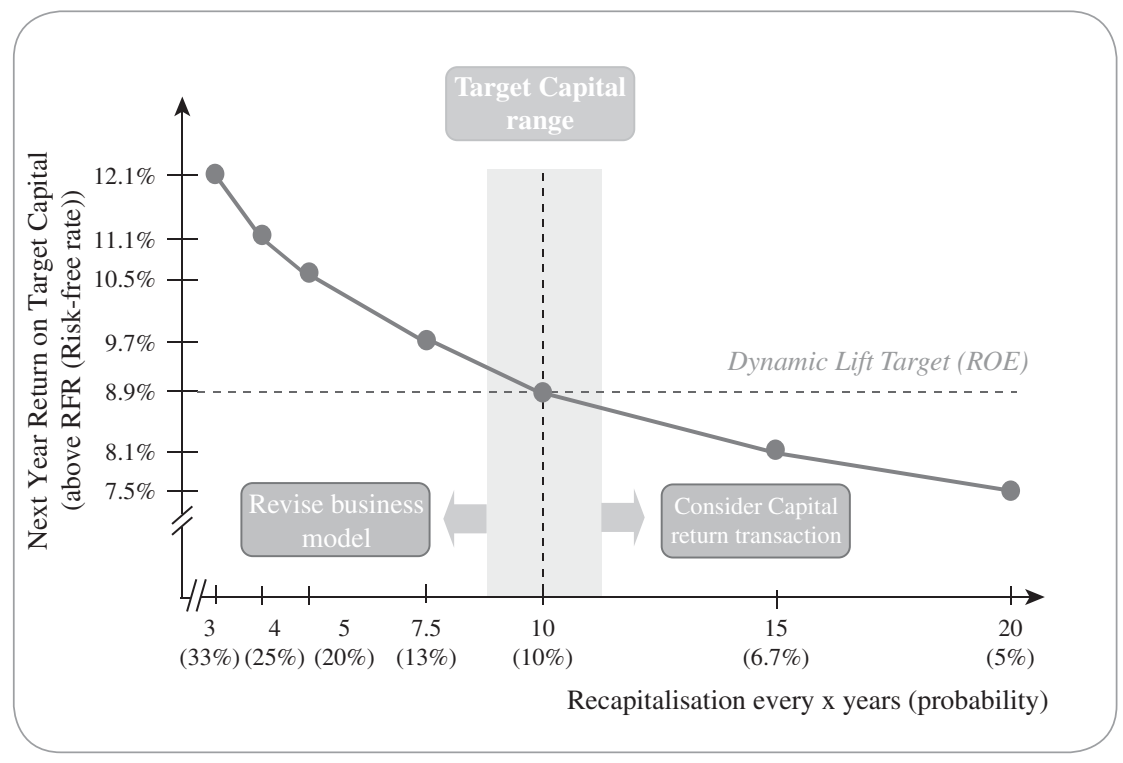

Figure 4. The Buffer Capital Policy is consistent with the return target Risk/Return trade-off for different recapitalisation probabilities.

allocate the target capital? The answer to the first question is obvious: excess capital should either be used to increase business profitably or be returned to the investors if this is not possible. Often a combination of both is optimal. The rest of this section deals with the second question: how should we allocate the target capital? 


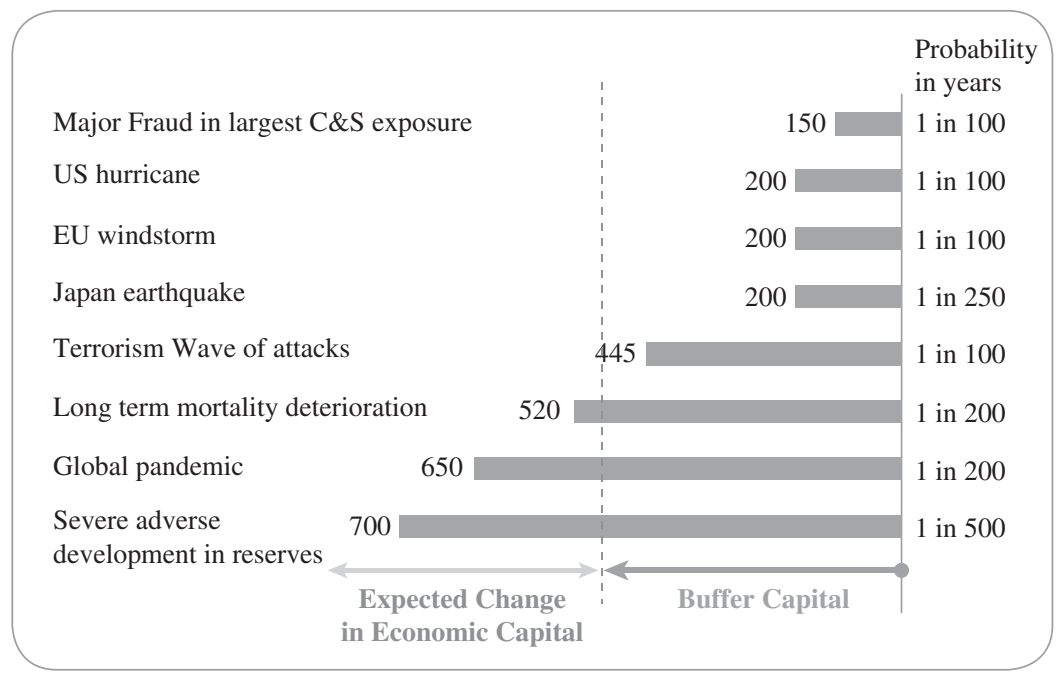

Figure 5. The Buffer Capital absorbs the single worst case scenarios Buffer Capital checked against single worst-case scenarios (examples) (in $€$ millons, net of retro).

Concepts of capital are crucial within a company when it comes to distributing the capacity profitably between the various different lines of business and the investment side. Optimal "capital allocation" to a line of business or a treaty is related to the risk contribution of the line of business or the treaty to the overall risk (e.g. expected shortfall) of the economic capital as measured by the internal model of the company. In a recent paper, Leibowitz ${ }^{10}$ from Morgan Stanley has shown that excess returns are better obtained by efficiently allocating risks to assets than by trying to have an active investment strategy. This means that charging a reinsurance treaty with the right amount of capital will contribute to creating an optimal portfolio of liabilities. The allocated capital must be profitable, that is, it must generate sufficient profit on average to meet the profit expectations communicated by management. In other words, capital becomes the "currency" for doing business and for measuring its profitability. In order to achieve this, systems for measuring the capital at risk should be in place. Moreover, the individual players must reach a consensus on how to calculate the capital at risk, and on how to allocate it.

Once such a system is in place, a business with less risk but the same premium will require less capital and will thus look more profitable. Conversely, a business that adds exposure to an already very exposed book will be penalised by more capital requirements and will thus appear less profitable. This way, the portfolio is steered towards more diversification and greater profitability. This is illustrated in Figure 6 by calculating the price of a set of CAT-layers with similar risk exposure the price of which changes when valued against the portfolio. We develop this further in the next section.

\footnotetext{
${ }^{10}$ Leibowitz (2005).
} 


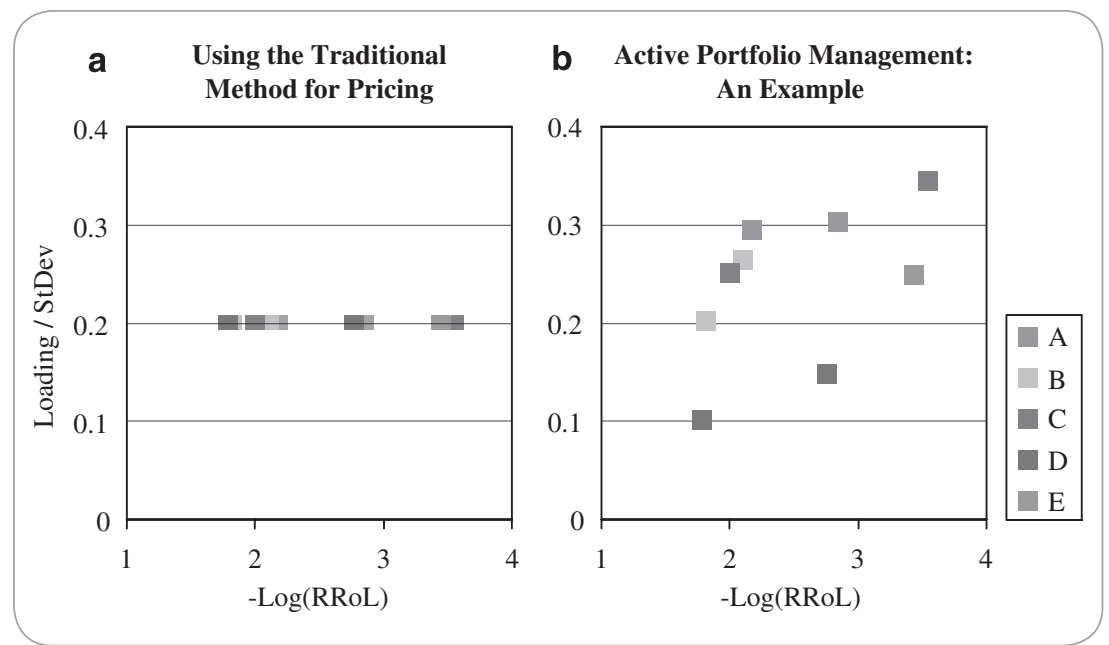

Figure 6. Risk loading for various CAT Programmes. (a) Using the standard deviation loading makes all these programmes lie on a straight line since they present very similar risk characteristics. Risk Rate on line: $R R O L=$ Expected Loss/Granted Limit. (b) Diversification on risk accumulation are favoured respectively penalised in the price. As a result, the pricing mechanism implicitly optimises the portfolio.

When it comes to measuring profitability of business and to defining targets, the entire target capital should be taken into account. The ROE target announced by the management can only be achieved if we allocate the entire target capital (including the buffer) to the risks and require that every risk produces on average the allocated target ROE. For practical purposes, we define two different profitability thresholds: the hurdle and the target. The hurdle is defined as the return required for covering all costs including cost of capital as derived from market expectations Capital Asset Pricing Model (CAPM). ${ }^{11}$ It must in principle be reached by every policy; otherwise we are not able to cover all our costs. Any policy written below hurdle should be either avoided or considered as an investment for future earnings. The target will be set in order to, on average over the cycle, meet the company's target: 900 bp above the riskfree rate. In certain circumstances, for instance during hard markets in Property \& Casualty (P\&C), the target could be set higher so as not to "leave money on the table". In others, it could be set lower in order to keep market shares. For life, as there is no real market cycle and contracts have a long-term effect, the target rate is not likely to vary from one year to the next. In any case, the choice of target should be a conscious management decision.

Deducing the hurdle and target from the company ROE objective is not straightforward because one needs to basically translate an annual objective of a balance sheet to a performance objective on a particular cash flow that is not necessarily limited to one year. There are clearly various ways of doing this. Here

\footnotetext{
${ }^{11}$ For a good review on this subject, see Fama and French (2004).
} 
we describe how we would approach the problem. In order to solve it, we assume that the company writes a portfolio of business that does not dramatically change from one year to the other, and thus the calendar year $R B C$ corresponds more or less to the $R B C$ computed to ultimate risk. The basis for this computation must be the amount of equity reported on the balance sheet. Given this number, the ROE target, and the CAPM cost of capital, it is possible to calculate the total target and hurdle profit the company must generate to reach its objective. For the total profit $A_{i}$, this is

$$
A_{i}=r_{i} \times C+E, \quad \text { where } i=h \text { or } t
$$

where $C$ is the amount of equity reported on the balance sheet, $E$ are the expenses to be covered during the year, and $r_{i}$ equals either the CAPM cost of capital or the ROE objective for $I=h$ (hurdle) and $i=t$ (target), respectively.

The total profit can then be split into the individual business units $k$ on the basis of the ratio of the individual $R B C, Q_{k}$, allocated to the total $R B C, Q$, of the entire portfolio. Thus, the target profit of an individual business unit $k$ yields

$$
A_{i, k}=A_{i} Q_{k} / Q
$$

We assume here that both the equity and the expenses are allocated in proportion to the $R B C$ allocated to the business, but it could be possible to separate the expenses from the equity and allocate them separately to each business unit $k$. The method has the merit of its simplicity. It can be discussed as to whether riskier business will require more expenses to be managed.

The business then generates this total profit from its investment income, ${ }^{11 \mathrm{~b}} I$, and its technical or underwriting income. Once the investment income (and its investment risk) allocated to a business unit $k$ is known, the rest of the total profit of a business unit $k$ needs to be generated by underwriting. This is in turn measured on the $R B C$ allocated to this particular business, and is modified by the investment risk, $S_{k}$. Thus, the underwriting target (and hurdle) rate, $R_{k}$, of the business unit $k$ can be computed from the income that needs to be generated over the $R B C$ allocated to the underwriting risk of the business unit $k$. Obviously, the investment risks and returns are now integrated in the underwriting performance for the hurdle and target rate:

$$
R_{i, k}=\left(A_{i, k}-I_{k}\right) /\left(Q_{k}-S_{k}\right), \quad \text { where } i=h \text { or } t
$$

Following this principle, it is relatively easy to deduce the target and the hurdle from the target ROE and the cost of capital allocation $Q_{k}$ as illustrated in Figure 6. Once a scheme is in place, ${ }^{12}$ it is possible to translate the performance objectives of the company in a required performance from the business.

\footnotetext{
${ }^{11 \mathrm{~b}}$ One can estimate the income generated by investment by looking at the duration of the reserves and setting a reasonable investment performance based on the risk free rate and a small spread above it.

${ }^{12}$ SCOR (2008).
} 


\section{Portfolio management and capital limits}

Why go through all this trouble in order to allocate capital to the various units of a firm? Simply because it is the best way to steer the portfolio towards higher profitability. In his seminal book on capital management, Matten ${ }^{13}$ remarks,

Whilst efficient capital allocation does not guarantee success, failure to make the best returns possible on the resources invested by shareholders will almost certainly guarantee sub-optimal performance in an increasingly competitive market. Allocating capital even on a relatively rudimentary basis - such as capital adequacy regulations - goes a long way to improving the efficiency of the resource utilisation.

If management is able to allocate an amount of the company's equity to a business unit, it can also measure the performance of this unit, and then reduce or increase the exposure according to the potential results of that particular line of business, leading to portfolio optimisation. Moreover, explicitly assigning capital to a business unit and relating the amount to the risk assumed by that unit facilitates the development of a risk management culture within the company. The simple fact that a monetary amount is assigned facilitates discussion among the various stakeholders as to the underlying assumptions that led to this amount in the first place.

Moreover, a very efficient way to insure the risk-reward strategy of the company is to set limits on the capital consumed by the various business units. This is particularly true in the case of the asset management of a reinsurance company. Asset management is not a core reinsurance business, and very often it is not even really clear how it should be managed. On the one hand, assets should be invested so as to produce high investment yields. On the other, the company should not take too much risk on the financial markets, in order to keep enough capacity for its core business. This is why we suggest limiting the amount of $R B C$ consumable by the asset managers to no more than 25 per cent of the total allocated capital in the Asset-Liability-Management (ALM) model. One can also add a limit to the rating agency capital that the company is willing to use for this activity. This limit does not need to be the same as for the internal model, as the risk model of rating agencies for assets differs substantially from our own models. A reasonable limit here would be, for instance, 15 per cent for S\&P capital (subject to revision with new models).

There is a subtle difference between the limits that we propose to set and our risk appetite. The limits are related to the company's risk tolerance, and should not be exceeded under any circumstances. Coming back to the 25 per cent limit for asset management, the risk appetite would usually be much lower than this, around 15 per cent. If we are already above the 15 per cent mark, let us say at 20 per cent, we should, in normal circumstances, already be taking measures to reduce our risk level so that we do not exceed the 25 per cent limit. We should also act in a similar way with other insurance risk limits.

\footnotetext{
${ }^{13}$ Matten (2000).
} 


\section{Conclusions}

This paper is about sound capital management for a reinsurance company. We hope that we have answered the question posed in the title. We see that prudent capital management requires more capital than simply the amount coming out of an internal or rating agency model.

We have thus introduced in this paper the concept of capital buffer to account for model uncertainty as well as to avoid asking shareholders to recapitalise the company too often. This buffer can be determined using the internal model and the probability of recapitalisation, but it is limited by the profitability objectives of the company, as shown in Appendix B.

Once the target capital for the company is determined, we show that its allocation leads to the determination of performance objectives for each contract, and that those objectives are best set by having fixed two rates: the hurdle rate that covers all expenses of the company including cost of capital, and the target rate that incorporates the company's target ROE and the current market cycle. We conclude by discussing the importance of capital allocation for steering the portfolio towards profitability, and show how it is possible to deduce target performance and exposure limits based on this allocation.

The concepts presented here have been derived for a reinsurance company. This is viewed as the natural breeding ground for such ideas, as this sector deals with the most extreme risks. We believe, however, that with certain adaptations due to the size of the contracts and the stronger influence of the law of large numbers, they can be adapted for insurance companies and other financial institutions.

\section{Acknowledgement}

The authors acknowledge interesting and challenging discussions while elaborating the concepts presented here with Marco Circelli, Markus Krall, Oliver Lang and Philippe Trainar.

\section{References}

Artzner, P., Delbaen, F., Eber, J. and Heat, D. (1997) 'Thinking coherently', Risk Magazine 10(11): 68-71.

Artzner, P., Delbaen, F., Eber, J. and Heat, D. (1999) 'Coherent measures of risk', Mathematical Finance 9(3): 203-228.

Basel Committee (1988) International convergence of capital measurement and capital standards, Technical Report Basel, July 1988, Committee on Banking Regulation and Supervisory Practices.

Bernstein, P.L. (2007) Capital Ideas Evolving, New York: John Wiley \& Sons.

Crouhy, M., Galai, D. and Mark, R. (2001) Risk Management, New York: McGraw-Hill.

Fama, E. and French, K. (2004) 'The capital asset pricing model: Theory and evidence', Journal of Economic Perspectives 18(3): 25-46.

Leibowitz, M. (2005) 'Alpha hunters and beta grazers', Financial Analysts Journal 61(5): 32-39.

Matten, C. (2000) Managing Bank Capital, Capital Allocation and Performance Measurement, 2nd edn., New York: John Wiley \& Sons.

Morisano, F. (1998) 'Managing capital resources efficiently to optimise shareholder value', Journal of Lending and Credit Risk Management, September: 28-32.

SCOR (2008) From Principle-Based Risk Management to Solvency Requirements. Analytical Framework for the Swiss Solvency Test, Paris: SCOR Studies.

Shimpi, P.A., Durbin, D., Laster, D.S., Helbling, C.P. and Helbling, D. (1999) Integrating Corporate Risk Management, New York: Swiss Re. 


\section{Appendix A}

\section{Mathematical definition of $R B C$ and solvency requirements}

The definition of $R B C$ is often left vague in the publications where it is discussed. We present here precise mathematical definitions in order to avoid any confusion, and because our way of calculating this quantity differs slightly from the pure solvency definition.

First, let us start with some notations:

$E V(X) \quad$ means economic value of the variable $X$

$\mathrm{A}_{i} \quad$ are the assets at time $t_{i}$

$L_{i} \quad$ are the liabilities at time $t_{i}$

$C_{i} \quad$ is the available capital at time $t_{i}$ discounted at $t_{0}$ where $C_{i}=E V\left(A_{i}\right)-E V\left(L_{i}\right)$

$\mathrm{P}_{i} \quad$ is the profit made at time $t_{i}$ discounted at $t_{0}$ where $P_{i}=C_{i}-C_{0}$

$E[X] \quad$ is the expectation of the stochastic variable $X$

$\operatorname{VaR}_{\alpha}(X)$ is the Value-at-Risk of the stochastic variable $X$ at the $\alpha$ probability

$E S_{\alpha}[X] \quad$ is the expected shortfall of the variable $X$ at the $\alpha$ probability

For ease of notation, we have not added here the Net Present Value (NPV), which usually expresses discounting. From the point of view of the shareholder, the risk is that he will not, at the end of the year, be able to reach the profit he expects. We thus define the $R B C$ as

$$
R B C=E\left[P_{1}\right]-E S_{\alpha}\left[P_{1}\right],
$$

where the 1 is for $t_{1}$ the end of the year. As the expectation of $C_{0}$ is $C_{0}$, the above expression can be simplified in terms of available capital at $t_{1}$ as follows:

$$
R B C=E\left[C_{1}\right]-E S_{\alpha}\left[C_{1}\right] .
$$

If we now turn to the regulatory solvency $R B C$ and the regulator solvency requirement, we can write the solvency $R B C_{s}$ as

$$
R B C_{s}=E S_{\alpha}\left[C_{1}\right] \geqslant 0 .
$$

This is the Swiss Solvency Test requirement. Solvency II will require the Value-at-Risk at 99.5 per cent to follow the above condition, but in terms of monetary amounts they are equivalent. Coming back to our definition, our own solvency requirement is that

$$
R B C=E\left[C_{1}\right]-E S_{\alpha}\left[C_{1}\right] \leqslant E\left[C_{1}\right],
$$

which is equivalent to

$$
R B C \leqslant E\left[P_{1}\right]+C_{0},
$$

and satisfies also the regulator's requirements. We note that

$$
R B C_{s}=R B C-E\left[P_{1}\right] .
$$


The two definitions differ by the expected economic profit for the year. This quantity constitutes the departure point for shareholder risk. The buffer $B$ is then defined as the 90 per cent quantile of the profit distribution: $\operatorname{VaR}_{0 \cdot 9}\left(P_{1}\right)$.

\section{Appendix B}

\section{Required capital and risk-return profile, limit for buffer capital}

As we have seen above, the choice of probability for the capital buffer is not arbitrary; in this appendix, we formalise this idea and deduce the theoretical boundaries to these choices.

If we define $\lambda$ to be the market risk premium for a total loss at the 99 per cent expected shortfall, and $z$ to be the risk-free rate, the market will thus expect that we reward our required capital $R$ at a level of: $z+\lambda$.

If $B=B(N)$ is the buffer representing the quantile of the (capital) distribution that has a 1 in $N$ probability of exhaustion, then, by default, the market will allow us to earn

$$
R(z+\lambda)+B z
$$

as $B$ must be invested risk-free.

If $T$ is the shareholders' premium above the risk-free rate charged on the aggregate of the required capital $R$ and the buffer $B$, then the shareholder will wish to see a result of

$$
(R+B)(z+T)
$$

Note that $\lambda+z$ (and hence $\lambda$ ) can be derived by relating the amount of reasonably expected economic return (i.e. the return on the economic balance sheet) less the cost of the buffer to the required capital. The shareholders' premium, $T$, must be derived by relating a translation to economic return of the target Generally Accepted Accounting Principles return (International Financial Reporting Standards return) to the economic capital. Thus, to make ends meet we must require that

$$
R(z+\lambda)+B z \geqslant(R+B)(z+T),
$$

which is equivalent to

$$
\frac{B(N)}{R} \leqslant \frac{\lambda-T}{T}
$$

Note that this clearly only works if $T$ does not exceed $\lambda$. If $T$ equals $\lambda$, then the shareholders should at any time be prepared to recapitalise. If the shareholders want the company to keep a buffer, they must accept an economic return on economic capital below the market risk premium. The question is why would they do so. The answer is twofold: first, the cost of recapitalisation is far from negligible, with at least 5 per cent of the total amount required by investment banks as fees that add to the 
influence of the distress on the share price. Second, the determination of risk capital is not a pure science, and is subject to a significant level of model risk. Shareholders need to allow for this uncertainty, which is where the buffer comes in.

Effectively, this means that given $\lambda, T$, and $N$, we must manage the capital and the portfolio (and the resulting distribution of capital) in such a way that

1. $R \times \lambda / T=R+B$ equals our available economic capital and

2. $B / R=(\lambda-T) / T$

that is, the ratio of the quantile of the (capital) distribution, which has a 1 in $N$ probability of exhaustion over the required capital, is equal to the ratio of the excess of market risk premium over shareholder risk premium.

This is a test we can perform on our portfolio on the basis of our internal model and/or extreme scenarios. Using the numbers we chose before $900 \mathrm{bps}$ for $T$, and a risk-free rate of around 3.5 per cent, we see in Figure 2 (assuming that this curve represents the risk/return profile of the entire company) that a buffer chosen at $1 / 10$ probability is consistent. Knowing both the buffer and $T$, we can compute $\lambda$, and we arrive at a value of around 1,050 bps.

Note that we use an inverse calculation. Normally, we should start from the market expectation and deduce the buffer and the target return. In reality, we see that there is a certain consensus among shareholders to ask reinsurers to produce $900 \mathrm{bps}$ above the risk-free rate over the cycle, and this corresponds, in our case, to a discount of about 150 bps on market expectations given the cost of raising capital and the uncertainty relating to the $\mathrm{RBC}$ computation.

\section{Appendix C}

\section{Glossary}

Economic Capital: The difference between the marked-to-market-value of the assets and the market-consistent value of the liabilities.

Available Capital: The economic capital deduced from the balance sheet at $t_{1}$ calculated at $t_{0}$. When done properly, this is the economic capital at time $t_{1}$.

Risk-Based-Capital (RBC): the quantity computed by the various models (internal, rating agency, solvency) for $t_{1}$. For the internal model, we suggest using the difference between the expected value and the 99 per cent expected shortfall of the economic capital at $t_{1}$.

Required Capital: The maximum of the internal model $R B C$, the capital requirements of the rating agencies model, and the solvency model, computed for $t_{1}$, at $t_{0}$.

Buffer Capital: The monetary amount above the required capital, which has an X per cent probability (we choose 10 per cent) of being exhausted, as calculated from the internal model computed for $t_{1}$, at $t_{0}$.

Target Capital: The monetary amount of capital the company needs to have at $t_{0}$ in order to be able to meet its obligations at $t_{1}$. In our definition, this is the required plus the buffer capital.

Signalling Capital: The difference between the required capital and the available capital. It can be different from the buffer capital if the company wants to expand the business in a multi-step period. 
Target Rate: The rate of return the company should produce on its target capital. We have communicated 900 bps above the risk-free rate over the cycle. The rate can be changed from one year to the next in order to achieve the target rate over the respective cycle.

Hurdle Rate: The rate of return the company needs to achieve in order to cover all its costs, including the costs of capital computed from a CAPM approach.

\section{About the Authors}

Jean-Luc Besson is Fellow of the Institut des Actuaires (France), holds a PhD in Mathematics, and has served as a University Professor of Mathematics and as Senior Vice President of Research, Statistics, and Information Systems at the FFSA (Fédération Française des Sociétés d'Assurance - Federation of French Insurance Companies). He was appointed Chief Reserving Actuary of the SCOR Group in January 2003, and has been Group Chief Risk Officer since 2004.

Michel M. Dacorogna holds a $\mathrm{PhD}$ and a habilitation in theoretical physics from the University of Geneva. After a post-doctorate at the University of California in Berkeley, he worked at Olsen \& Associates, a company developing real-time trading models for financial markets. He started his career in reinsurance at Zurich Re. In 2002, he took over the ALM model for Converium and became the secretary of the ALM committee and advisor to the investment office. Since 2006, he has been responsible for the Swiss Solvency Test project. The co-author of: An Introduction to High Frequency Finance, he has also published numerous papers in scientific journals. $\mathrm{He}$ is an associate editor of Quantitative Finance and the Studies in Nonlinear Dynamics \& Econometrics.

Paolo De Martin graduated from Ca' Foscari University, Italy, with a degree in Business Economics. He subsequently spent two years in the optical business as founder and managing partner of an eyewear manufacturer. In 1997, he joined GE's internal auditing and consulting group, charged with assignments in multiple GE businesses in the Americas, Europe and Asia-Pacific. In 2001, Paolo De Martin was promoted to Executive Manager for GE Capital Europe, before joining GE Insurance Solutions as Financial Planning and Analysis Manager for Global Property and Casualty Reinsurance. In 2003, he was appointed CFO of GE Frankona group, before becoming Chief Financial Officer of Converium in July 2006. In September 2007, Paolo De Martin was appointed Group Chief Financial Officer of SCOR.

Michael Kastenholz holds a PhD in Mathematics from the University of Cologne, and is a Fellow of the German Actuarial Association (Deutsche Aktuar VereinigungDAV). He started his professional career as an actuary at Gerling Global Re, later becoming their interim Group CFO and Member of the Board of Management. From 2003 to 2007, he held the office of CFO and Deputy CEO (from 2005) of the Revios Reinsurance Group. He further served as the chairman of the board of Revios 
Reinsurance Ireland Ltd. He was appointed CFO of SCOR Global Life and Deputy CFO of SCOR in November 2006. In November 2007, he was appointed Deputy CRO of SCOR Group.

Michael Moller holds a PhD in Economics from the University of Konstanz. He is in charge of the development of SCOR Group Internal model and SCOR Switzerland Swiss Solvency Test. Before joining SCOR (and Converium), he worked for Zurich Financial Services (ZFS) in the Corporate Customer Division and the Investment Department. At ZFS, he was concerned with the development of a pricing model for large corporate clients, pricing of large accounts, and analyses of investments, and provided consulting on the implementation of ALM models. 